1 Universidade do Estado do Rio de Janeiro (Uerj) Rio de Janeiro (RJ), Brasil. leticia_nutricionista@ hotmail.com.br

\section{Os sentidos da cozinha de Centros de Atenção Psicossocial e a inserção do nutricionista no cuidado em saúde mental}

\author{
The senses of the kitchen of Psychosocial Care Centers and \\ nutritionists performance in mental health care
}

Leticia Almeida', Cristiane Marques Seixas' ${ }^{\mathbf{1}}$, Francisco Romão Ferreira', Fabiana Bom Kraemer ${ }^{\mathbf{1}}$

\begin{abstract}
RESUMO Como produto das Reformas Psiquiátrica e Sanitária, surgiram os Centros de Atenção Psicossocial (Caps), dispositivos para pensar a reinserção de pacientes psiquiátricos na sociedade em 2001. A inserção do nutricionista nesse contexto ganhou espaço consonante a sua crescente atuação no Sistema Único de Saúde. Este artigo objetivou analisar os sentidos da cozinha em três Caps do Rio de Janeiro, a formação e a atuação dos nutricionistas. Optou-se pela modalidade de ensaio analítico, adotando como ponto de partida pressupostos teóricos da clínica ampliada, que entendem cuidado como uma experiência de troca entre sujeitos e responsabilização mútua, e do campo alimentar-nutricional como problema complexo. Nesse sentido, a discussão foi sistematizada em dois momentos: Entre panelas, tensões, saberes e sabores: a cozinha como espaço terapêutico; e Caps: desafios para formação e atuação do nutricionista. A análise toma a cozinha como espaço social e discute a permanência de uma atuação do nutricionista no cuidado em saúde mental moldada pelo modelo biomédico, construindo uma prática descontextualizada. Conclusivamente, o ensaio não buscou respostas ou afirmações verdadeiras, mas fez emergir a percepção de um problema que possibilita refletir sobre a prática dos nutricionistas nos Caps, contribuindo para a consolidação das propostas da Reforma Psiquiátrica brasileira.
\end{abstract}

PALAVRAS-CHAVE Serviços de saúde mental. Alimentação coletiva. Nutricionistas.

ABSTRACT As a product of the Psychiatric and Health Reforms, the Psychosocial Care Centers (Caps) emerged, as devices to think about the reinsertion of psychiatric patients in society in 2001. The insertion of the nutritionist in this context gained space, in line with their growing performance in the Unified Health System. This article aims to analyze the senses of the kitchen in three Caps in Rio de Janeiro, the training and the performance of nutritionists. We opted for the analytical testing modality, adopting the theoretical assumptions of amplified clinic as a starting point, which understand care as an experience of exchange between subjects and mutual accountability, and of the food-nutritional field as a complex problem. This way, the discussion was systematized in two moments: Among pans, tensions, knowledge and flavors: the kitchen as a therapeutic space; and Caps: challenges for professional qualification and performance of nutritionists. The analysis looks at the kitchen as a social space and discusses the continuity of nutritionists performance in mental health care shaped by the biomedical model, generating a decontextualized practice. In conclusion, the essay did not seek answers or true statements, but it did raise the perception of a problem that makes it possible to reflect on the practice of nutritionists in Caps, contributing to the consolidation of the proposals of the Brazilian Psychiatric Reform.

KEYWORDS Mental health services. Collective feeding. Nutritionists. 


\section{Introdução}

A Reforma Psiquiátrica brasileira ocorreu no início da década de 1970, estimulada pelo movimento da Reforma Sanitária, tendo como eixo central uma nova organização do cuidado e uma rearticulação das práticas de saúde com ênfase especial à desinstitucionalização da doença mental'. A Reforma Sanitária que a precedeu possibilitou o redimensionamento do conceito de saúde, antes restrito ao diagnóstico médico feito por especialistas, que passou a ser pautado pela garantia da vida ${ }^{2}$. Amarante ${ }^{3(2)}$ defende que, em uma dimensão cultural do processo de Reforma Psiquiátrica, o objetivo maior não foi a “[...] transformação do modelo assistencial [...], mas a transformação do lugar social da loucura, da diferença e da divergência". A percepção dos usuários como sujeitos de direitos e a defesa da vida passaram a ser premissas fundamentais do cuidado ao paciente ${ }^{3}$.

Com o objetivo de viabilizar a desinstitucionalização do cuidado em saúde mental, os Centros de Atenção Psicossocial (Caps) surgiram no final da década de 1980 e são, até o momento, territórios considerados estratégicos para reestruturar o cuidado aos pacientes psiquiátricos com transtorno mental grave e persistente.

A noção de território reconhecida pelos Caps vai muito além de um espaço de delimitação geográfica e/ou uma região administrativa. Para além de meros espaços físicos, os Caps estão em articulação recíproca com a sociedade e possuem papel essencial sobre a vida deste ou daquele indivíduo e do corpo social que compõem o cotidiano do território. Segundo Freire ${ }^{4}$, o louco deixou de assumir o papel de objeto e passou a ocupar o lugar de sujeito, com escolhas, responsabilização, no sentido da implicação desse sujeito na tomada de decisões e na (re)construção da própria vida. Se antes essas ações se limitavam ao espaço físico de uma instituição, os hospitais psiquiátricos, com a Reforma Psiquiátrica, passaram a acontecer nos espaços que a vida oferece de circulação e sociabilidade.
Os Caps surgiram, à época, como dispositivos estratégicos da Reforma Psiquiátrica e expandiram-se a partir da aprovação, em abril de 2001, da Lei $n^{0} 10.216^{5}$ que fundamenta a atual Política Nacional de Saúde Mental em sua proposta de consolidar um modelo de atenção à saúde mental aberto e de base comunitária e territorial. Trata-se de um modelo cujo paradigma é a garantia da livre circulação das pessoas com transtornos mentais pelos serviços, comunidade e cidade, oferecendo o cuidado baseado nos recursos que a comunidade oferece, em que se valoriza o protagonismo do sujeito.

A questão da loucura deixa então de ser domínio exclusivo da psiquiatria e passa a alcançar os espaços da cidade, das instituições e da vida dos cidadãos e daqueles que por elas passaram em algum momento da vida, demandando a constituição de uma nova rede de cuidado em saúde mental. É nesse contexto ampliado que o nutricionista se insere, ainda que pouco se discuta sobre essa inserção. Esse profissional ganhou espaço no campo da saúde com a própria criação e consolidação do Sistema Único de Saúde (SUS), mas, sobretudo, com a inserção na Constituição Brasileira de $1988^{6}$ da alimentação como um direito humano. Contudo, apesar da ampliação do campo de atuação profissional, não se observa um correlato desdobramento na formação que busque contemplar as necessidades oriundas da interface entre os campos da alimentação e nutrição e da saúde mental.

As políticas públicas provenientes do processo de Reforma Psiquiátrica garantem o direito à alimentação dos usuários dos Caps, entretanto, esses mesmos documentos pouco dizem sobre as questões relativas ao ato de alimentar e ser alimentado. Trata-se aqui de diferenciar os aspectos relativos ao nutrir entendido como a ingestão dos nutrientes necessários à manutenção da vida - e o comer em sua dimensão biopsicossocial que vai além do ato mecânico de ingerir um alimento ${ }^{7}$.

Dessa maneira optou-se por uma modalidade textual de ensaio analítico, com ênfase na 
argumentação e interpretação, para analisar os sentidos da cozinha dos Caps na prática clínica nutricional e a formação e a atuação do nutricionista em saúde mental a partir de uma perspectiva de clínica ampliada.

Para tanto, o ensaio analítico toma como 'lugar de olhar' a vivência de um nutricionista em três Caps localizados na região metropolitana do município do Rio de Janeiro, sendo um Caps adulto, um Caps $\mathrm{AD}$ (álcool e drogas) e um Capsi (infantojuvenil). Tratou-se de um recorte no percurso de pesquisa acadêmica que teve como objeto de estudo a atuação do nutricionista no campo da saúde mental; em que as observações com inspiração etnográfica foram registradas em diário de campo, e as situações trazidas para pensar os sentidos que cercam o ato de se alimentar aparecem como fragmentos dessa experiência, sendo analisadas a partir de pressupostos teóricos da clínica ampliada ${ }^{8} \mathrm{e}$ no entendimento do campo alimentar-nutricional como espaço social complexo. Nos Caps, a garantia do direito humano à alimentação aparece legitimada na Portaria $n^{\circ} 336^{9}$, ao incluir o fornecimento de refeição entre as atividades que deverão ser desenvolvidas pela assistência de um Caps. Assim, pacientes assistidos em 1 turno (4 horas) deverão receber uma refeição diária, os assistidos em 2 turnos (8 horas) receberão duas refeições diárias, e pacientes que permanecerem no serviço por 24 horas contínuas receberão 4 refeições diárias.

A alimentação é entendida no cumprimento do direito previsto e garantido tanto nos documentos oficiais que norteiam a atuação profissional do nutricionista quanto nos documentos que regularizam os Caps. $\mathrm{O}$ não cumprimento desse direito poderia levar ao descredenciamento do serviço e seu fechamento. $\mathrm{O}$ gestor, com a equipe, necessita assegurar esse direito, para que suas ações não demonstrem negligência no cuidado. Todavia, há uma diferença no processo de alimentação do corpo biológico e o fenômeno da alimentação em sua dimensão simbólica, com os sentidos que a comida pode assumir em termos culturais, afetivos, religiosos e institucionais. Assegurar os nutrientes necessários para a manutenção do corpo é diferente de oferecer alimentação com dignidade e respeito ao direito a uma alimentação adequada.

Interpretar a alimentação pela ótica do direito pode apresentar limites, no entanto, precisamos levar em consideração que alimentar-se é um ato essencial à vida, reforçando o que prega um dos principais objetivos do cuidado ao paciente acometido por transtornos psiquiátricos. Apesar do ato de comer e da comida estarem repletos de significados sociais e subjetivos, não podemos negar que também nos alimentamos por uma necessidade vital ${ }^{10}$. Os espaços nos quais as pessoas se alimentam também são ambientes de sociabilidade, familiaridade, trocas simbólicas, hierarquias e relações sociais.

Se nos espaços domésticos, na vida cotidiana e no mundo do trabalho a cozinha é sempre um lugar diferente, onde se falam coisas que geralmente não são ditas em outros locais, nos Caps, a lógica não é outra. A cozinha é um lugar de intimidade e troca de ideias, um ambiente que permite uma certa informalidade e a possibilidade de criação de vínculos. Segundo Leonardo Boff,

[...] há algo nos seres humanos que não se encontra nas máquinas, surgido há milhões de anos no processo evolutivo quando emergiram os mamíferos, dentro de cuja espécie nos inscrevemos: o sentimento, a capacidade de emocionar-se, de envolver -se, de afetar e de sentir-se afetado. Um computador e um robô não têm condições de cuidar do meio ambiente, de chorar sobre as desgraças dos outros e de rejubilar-se com a alegria do amigo. Um computador não tem coração. Só nós humanos podemos sentar-nos à mesa com o amigo frustrado, colocar-Ihe a mão no ombro, tomar com ele um copo de cerveja e trazer-Ihe consolação e esperança. Construímos o mundo a partir de laços afetivos. Esses laços tornam as pessoas e as situações preciosas, portadoras de valor. Preocupamo-nos com elas. Tomamos tempo 
para dedicar-nos a elas. Sentimos responsabilidade pelo laço que cresceu entre nós e os outros $^{11(50)}$.

A mesa que está presente nesses espaços, além de fazer parte do mobiliário, é um lugar simbólico de troca, de compartilhamento de ideias e de informações. Ela é utilizada por usuários e profissionais, juntos ou separados, e configura um lugar de respeito mútuo. No espaço da cozinha, seja pela garantia e cumprimento do direito à alimentação, seja pelo direito de dividir a mesma mesa, pode-se agregar valores, assim como estreitar os vínculos entre usuários e profissionais. A cozinha dos Caps pode aparecer nesse cenário como peça fundamental, sendo considerada um espaço privilegiado de escuta e, portanto, um espaço terapêutico ao ser pensada a partir do conceito de clínica ampliada ${ }^{8}$. Um ambiente que contribui para a aproximação entre profissional e usuários, além de integrar a família e a comunidade e propiciar a valorização da escuta.

\section{Entre panelas, tensões, saberes e sabores: a cozinha como espaço terapêutico}

O conceito de clínica ampliada 8 é uma das principais contribuições construídas nos desdobramentos das reformas sanitária e psiquiátrica, pois ele propõe a ampliação das bases conceituais que passam a avançar para além da racionalidade clínica da biomedicina. Além de incluir as dimensões social e subjetiva nas práticas, a clínica ampliada visa a atuação interdisciplinar, em que a relação clínica contempla uma experiência de troca não hierárquica entre sujeitos que permite reconstruir as relações de poder na equipe e com os usuários e sua rede sociofamiliar.

Outrossim, Demétrio ${ }^{12}$ aponta que tal modelo segue na contramão de uma cultura técnica e de verticalização das relações, sendo a ampliação da clínica nutricional necessária por promover uma expansão do olhar técnico-nutricional, ampliação da escuta, tornando-a mais sensível, além de reavaliar as demandas e expectativas. Nesse sentido, as cozinhas nos Caps tornam-se potenciais espaços para construção de vínculo e confiança no tempo, visto que é um espaço que nos dá uma visão de informalidade, no qual os laços podem se estreitar, as minúcias podem ser observadas e a prática clínica pode acontecer sem o enquadre tradicional com seus equipamentos de avaliação, formulários, receituários e, sobretudo, sem a barreira da soberania do saber biomédico.

Em uma concepção biomédica, a cozinha não seria um espaço terapêutico strictu senso, mas somente um lugar a mais onde as pessoas, os profissionais e os usuários iriam para nutrir seus corpos. Uma cozinha pode ser considerada um local que vai além de um somatório de utensílios característicos e emblemáticos, pode ser entendida como um espaço de comensalidade, não sendo reduzida a um simples lugar de distribuição de refeições. Esse ambiente, por seu potencial de trocas, convívio, estreitamento de vínculos e afetos, é o espaço (informal) em que os pacientes e familiares podem falar abertamente de suas angústias e aflições, no intervalo de um café, sem a barreira que uma mesa de consultório pode ocasionar.

O espaço da cozinha nos Caps pode ser considerado um ambiente no qual questões relacionadas com a clínica psicossocial podem ser abordadas, como, por exemplo, assuntos relativos a tentativas de suicídio; relatos de esgarçamento dos laços familiares ou relatos que remetem à experiência com o uso de drogas. Para o profissional de saúde mental, independentemente da especialidade, esses relatos não são banais. Esse espaço permite ao usuário uma sensação de acolhimento e coloca o ambiente da cozinha como protagonista no processo de cuidado. Ela, portanto, também é um espaço terapêutico, na medida em que não constitui uma circunstância individual de tratamento, mas um local em que se estabelecem laços sociais e que convoca o sujeito a se dispor ao outro por propiciar condições 
favoráveis para promoção de saúde em seu sentido mais amplo. Para além da cozinha, há a comida.

A comensalidade engloba todos esses elementos, visto que ela incorpora a dimensão cultural e social por meio do compartilhamento da mesa; do comer junto, atuando de maneira simbólica, que ultrapassam as barreiras biológicas. Além disso, esse conceito compreende que 'o que se come, onde, como e com quem se come' não são fenômenos isolados do sujeito e da sociedade, revelando as hierarquias sociais orquestradas pela comida lançada boca adentro ${ }^{7,13}$. O preparo das refeições nos Caps estudados é realizado em uma cozinha central administrada por uma empresa prestadora de serviços de alimentação, a mesma que presta serviços para rede hospitalar municipal do Rio de Janeiro. A escolha da empresa é feita mediante processo licitatório, e a estrutura do cardápio e tudo o que se relaciona com o preparo das refeições são estabelecidos em termo de referência, como, por exemplo, o tamanho da porção das preparações, a incidência dos diversos tipos de cortes de carnes (patinho, miolo de alcatra, filé de peito de frango, coxa de frango, filé de merluza entre outros), a consistência da refeição (dieta normal, pastosa, líquida, semilíquida), a suplementação alimentar, ou seja, uma cota adicional de alimentos destinada a prevenir ou corrigir carências nutricionais.

Apesar de este ensaio se debruçar no universo dos Caps, falar dessa cozinha é, sem dúvida, falar dos serviços de refeições fornecidos para os demais Caps espalhados pelo país. A consistência das refeições, por vezes, é criticada pelos usuários, em uma nítida crítica ao que é imposto pelos termos de referência entre governo e empresas prestadoras de serviços de alimentação, que consideram que a refeição se destina à população idosa egressa dos hospitais psiquiátricos e que é, em geral, desprovida de dentes e de escolhas.

No Caps adulto, o espaço físico da cozinha é composto de dois ambientes: um que acomoda um fogão, utilizado tanto em momentos pontuais como para aquecer a água para fazer o café da equipe de trabalho ou para preparar almoço para a equipe em momentos festivos ou de comemoração; e outro ambiente composto por mesas com bancos fixos para que os pacientes realizem suas refeições. Nessa cozinha, existe uma autorização prévia para os pacientes realizarem as refeições que são oferecidas no serviço, a qual é dada pelo profissional técnico de referência ${ }^{\mathbf{1 4}}$ que é responsável por monitorar o usuário, o contato com a família, além de acompanhar e avaliar as metas traçadas no projeto terapêutico do paciente; assim, muitas vezes, suas atribuições podem se estender para demandas burocráticas, assistenciais e gerenciais, que ultrapassam o campo da clínica. Para Silva ${ }^{15}$, inserir o profissional de referência para atender às práxis e aos princípios éticos da Reforma Psiquiátrica permite mudanças no modo de trabalho e reinvenção no modo de agir e cuidar do outro. Nem todos os pacientes realizam as refeições no Caps, apenas quando esta é uma demanda do próprio paciente ou quando o profissional avalia que a alimentação poderá influenciar positivamente no tratamento.

No Caps AD, assim como no Caps adulto, a autorização para os pacientes realizarem as refeições na unidade vem por meio de um combinado com seu técnico de referência. Já os usuários que ocupam os leitos de acolhimento à crise têm o direito previamente assegurado de realizar as refeições no Caps, tais como o café da manhã, almoço, lanche da tarde e jantar, e ainda partilham desse espaço ao longo do dia, em horários diferenciados do momento de fazer a refeição.

Nos momentos de comemoração, a cozinha do Caps AD é utilizada para almoços festivos da equipe. No cotidiano, apenas alguns membros da equipe almoçam nesse refeitório, e outros saem para almoçar fora do serviço em restaurantes da região. Os que comem no refeitório são os que levam marmita ou compram quentinhas. Nesse Caps, não existe nenhum funcionário público, sendo todos contratados por Organizações Sociais, ou seja, pessoa jurídica de interesse social e de utilidade pública, 
associação civil e sem fins lucrativos. Dessa maneira, o benefício relacionado com a alimentação é disponibilizado por meio de vale alimentação ou refeição.

$\mathrm{O}$ almoço e o jantar são entregues pela empresa prestadora de serviços em quentinhas e dispostas acompanhadas de talheres, sobremesa e refresco sobre jogos americanos, à mesa, pela copeira. O café da manhã e o lanche da tarde são servidos individualmente, e apenas o café com leite é porcionado no momento da refeição. As quentinhas são identificadas pelo nome de cada usuário que fará a refeição no Caps; e, em caso de sobra, os que desejarem podem repetir a refeição. As sobras só acontecem caso algum usuário não queira se alimentar naquele momento, pois as quantidades disponibilizadas são predefinidas contratualmente, não podendo solicitar quantidade extra de refeições.

A cozinha do Caps AD está envolta por tensões, e a dimensão da comensalidade se manifesta também pelos conflitos apresentados ali que procuram ser mediados pelos profissionais, demandando a presença destes no momento das refeições. Observa-se que se reunir durante a refeição é também um meio de comunicação e fortalece o grupo contribuindo para sua coesão ${ }^{16}$. Os profissionais que ali estão nos fazem pensar que não compartilham da convivialidade do grupo, uma vez que a causa principal da sua presença é o desacordo dos usuários às regras da instituição. Compartilhar a comida é também compartilhar sensações ${ }^{16}$ e permite aos usuários do Caps $\mathrm{AD}$ expressar sua identidade.

Algumas experiências em torno da mesa evidenciam o quanto o momento das refeições mobiliza os usuários a apresentar suas opiniões e extrapola o comer em seu sentido restrito, nutricional. A comida une os usuários nesse espaço marcado pela loucura.

O uso dos talheres (garfo ou colher) exemplifica uma dessas experiências. É habitual a comida estar acompanhada de talheres e de copos de plástico, já que não é incomum assistir ao uso dos talheres como armas - de tal modo que a discussão sobre a inclusão de talheres de metais e o uso de facas pelos usuários no âmbito do debate impulsionado pela Reforma Psiquiátrica e a proposta de reinserção do paciente na comunidade por meio dos Caps fragmentam opiniões e, muitas vezes, sequer são considerados passíveis de debate.

Se pensarmos que a comensalidade considera o 'como comer', a autonomia do paciente fica comprometida na impossibilidade de escolha do talher para fazer a refeição, assim como comer em 'quentinhas' ou ainda comer um iogurte sem auxílio do talher. As situações vivenciadas na cozinha do Caps colocam em debate a ritualização das refeições e a corporificação de seus elementos convertidos em meios de distinção social17 entre o adulto 'normal', que faz uso de talheres de metal, e o louco, com seu garfo ou colher de plástico para que não sejam usados como armas, exemplificando o processo civilizador do homem ocidental.

Outro tema em torno da mesa que reúne o grupo de usuários diz respeito à consistência da comida. A instituição, tendo como referência o modelo asilar, em que a maioria dos 'internos' é composta por população idosa e com poucos dentes, prioriza uma refeição de consistência branda, ou seja, aquela composta por preparações bem cozidas e que facilitam a mastigação e a digestão. No entanto, discussões e queixas são constantes, visto que os usuários dos Caps são pessoas mais jovens e com demanda de escolha 'do que comer'. A carne geralmente é palco de desentendimento. Se ela deve ser servida em cubos ou em bifes. Uns argumentam que os pacientes podem sofrer engasgos com risco de morte. Outros, que a carne em bifes propicia o uso de garfos e facas com supervisão da equipe eliminando o uso das colheres.

Essas vivências apontam para a complexidade do ato de se alimentar no contexto dos Caps. Podemos resgatar no louco o estigma de periculosidade e descontrole sobre seus impulsos ${ }^{18}$ distanciando-o das 'boas maneiras' de compartilhar uma refeição projetada para afastar a violência e distanciar o ser humano 
do comportamento animal, irracional. Pode-se compreender que o momento das refeições é um mosaico de relações e interações ${ }^{19}$, com uma linha tênue entre a descontração e o conflito, podendo, ao mesmo tempo, protagonizar momentos de acolhimento e de tensões.

No espaço da cozinha dos Caps, existem diferentes códigos e convivem diferentes lógicas que nem sempre são harmônicas. Na perspectiva do gestor, do profissional de saúde ou do usuário, uma faca não é simplesmente uma faca; isoladamente não faz sentido. O que seria um ato corriqueiro em outro espaço, como distribuir talheres para a refeição, no Caps, assume diferentes sentidos e nos permite compreender os significados do momento vivido.

A constante integração das pessoas, umas com as outras, com o meio social que as cerca se apoia nas crenças e valores de cada um e de todos, de tal modo que, na prática cotidiana do ato de comer, são desvelados sentidos dispersos na cultura e naturalizados na rotina. Os debates acerca da consistência dos alimentos ou do uso de talheres específicos, aqui interpretados como símbolos que comunicam, mostram valores instalados na cultura, interiorizados pelas experiências singulares, (re)construindo significados com o outro. Não se trata de meras opiniões, mas de significados estabelecidos sobre o usuário da saúde mental a partir dessas interações. Trata-se de um sistema de símbolos incorporados em uma interação recíproca, que se materializam em comportamentos e compreendem as representações atribuídas ao grupo sociocultural.

Assim como Geertz ${ }^{20(16)}$ exemplifica que os "[...] tiques nervosos, as piscadelas, as falsas piscadelas, as imitações, os ensaios das imitações são percebidos e interpretados [...]” e são dependentes do contexto e de outras variáveis, no espaço da cozinha, os símbolos são expressos na informalidade da mesa como ideias, e são dependentes das estruturas de pensamento e da cultura.

No espaço da cozinha, outras interações estão presentes, e a importância da figura do copeiro (aquele que serve a comida ao usuário do Caps) no controle sobre a alimentação vai sendo construída na dinâmica social. Na maioria das vezes, eles são os que efetivam as regras definidas pelo nutricionista. Este, por sua vez, tem a conduta nutricional embasada em evidências científicas e em parâmetros especificados, por exemplo, em guias alimentares e diretrizes estabelecidas por sociedades profissionais, determinando, assim, a quantidade de comida e o número de refeições, entre outras formas de decidir quanto e como o outro irá se alimentar naquele lugar. $\mathrm{O}$ copeiro, em muitas situações, é a personificação do limite, da escolha e até mesmo do cumprimento de ordens dadas pelo profissional de nível superior.

Se um símbolo resulta da associação de um objeto com outro gerando significados com diferentes sentidos para diversos atores, é nessa interação, nos quais os sujeitos estão imersos, que o copeiro passa a ser percebido como o elemento que controla a dieta, que decide se o usuário irá comer ou não um alimento, como o pão ou o café. A partir dessas experiências, é ao copeiro que o usuário solicita autorização para comer um determinado alimento - e o profissional pode ser ainda adjetivado de 'bonzinho' ou não por ocupar um lugar de fornecer um item tão importante na cultura brasileira: o café.

\section{Caps: desafios para formação e atuação do nutricionista}

Para contextualizar a constituição da profissão, vale salientar que o primeiro curso de graduação para formação de profissionais dietistas foi criado em 1902, na Universidade de Toronto - Canadá21. O pioneirismo das dietistas se deu nas antigas universidades europeias, em paralelo ao surgimento das ciências da nutrição. A formação era realizada por médicos especialistas, que treinavam as enfermeiras nas cozinhas dos hospitais no preparo de dietas especiais ${ }^{22}$.

L'abbate ${ }^{23}$ defende que os cursos de Nutrição foram criados no Brasil como processo de modernização da economia brasileira do 
Estado Novo, durante a presidência de Getúlio Vargas, porém podemos dizer que as origens da Nutrição no País divergem. No dia 24 de outubro de 1939, foi criado o primeiro curso de Nutrição no Brasil, na Faculdade de Saúde Pública do estado de São Paulo. Esse curso teria duração de um ano, dividido em quatro períodos ${ }^{24}$. Em 1949, no dia 31 de agosto, nasceu a Associação Brasileira de Nutricionistas (ABN), no Rio de Janeiro, capital da República naquela época, passando a se chamar posteriormente de Federação Brasileira das Associações de Nutricionistas (Febran), tendo como base de atuação os nutricionistas, técnicos e estudantes de nutrição. Atualmente, a instituição é conhecida como a Associação Brasileira de Nutrição (Asbran), que possui caráter técnico, científico, cultural e social e é composta por filiados às Associações de Nutrição dos estados brasileiros ${ }^{25}$.

Quase 20 anos depois, no dia 4 de setembro de 1959, o deputado Josué de Castro apresentou na Câmara Federal o projeto de Lei ${ }^{\circ}$ 904/59, que dispunha sobre o ensino superior em nutrição, regulando o exercício da profissão e outras providências. Este foi encaminhado à Comissão de Justiça da Câmara para apreciação do diretor de ensino superior, sendo aprovado ${ }^{25}$. Nas décadas de 1960 e 1970, houve um aumento do número de cursos de nutrição no País, totalizando sete em todo o Brasil, todos vinculados a instituições públicas, ofertando cerca de $\mathbf{5 7 0}$ vagas anuais ${ }^{\mathbf{2 6}}$.

Nesse mesmo período, iniciou-se o processo de reconfiguração da formação do profissional nutricionista, até então centralizado em dois tipos de profissional: um voltado para a elaboração e orientação dietética dentro dos serviços de atenção à saúde; e outro para a administração dos Serviços de Alimentação da Previdência Social (Saps). Esses serviços, criados em 1940, marcaram a melhora da qualidade nutricional da alimentação dos trabalhadores, apesar de terem avançado pouco na compreensão de que uma cozinha não estaria apenas a serviço da produção de refeições carreadoras de nutrientes. Iniciou-se, então, o processo de institucionalização do campo da nutrição em saúde pública, particularmente no interior dos países latino-americanos ${ }^{27}$.

Vasconcelos ${ }^{27}$ ainda defende que a emergência desse campo científico, denominado de nutrição e saúde pública, nutrição social ou nutrição e saúde coletiva, foi produto do processo histórico de especialização e divisão do trabalho/saber no interior da complexa e multidisciplinar ciência da nutrição, constituída entre as décadas de 1930 e 1940.

Cabe destacar que o Saps apresenta especial importância, pois consideramos plausível assumir que o núcleo da alimentação coletiva está intimamente relacionado com a instituição, uma vez que algumas de suas atividades eram a produção e distribuição de refeições, somadas à formação de profissionais para executar essa tarefa. Esse núcleo de práticas e saberes tem como locus de atuação as 'cozinhas' denominadas, no campo da alimentação e nutrição, no Brasil, de unidades de alimentação e nutrição. Assim, esse espaço de atuação do nutricionista, quando inserido em unidades de saúde mental, demanda profissionais qualificados em ambas as áreas de atuação dessa categoria, de acordo com o Conselho Federal de Nutricionistas $(\mathrm{CFN})^{\mathbf{2 8}}$, a saber: nutrição em alimentação coletiva e nutrição em saúde coletiva.

Como área de prática profissional, a nutrição em alimentação coletiva tem desempenhado um papel importante no desenvolvimento da área de alimentação e nutrição no Brasil desde a criação do Saps, incluindo a articulação com programas de previdência estatal (por exemplo, Programa de Alimentação do Trabalhador), e como grande área de atuação do nutricionista ${ }^{29}$. Já a nutrição em saúde coletiva, segundo Vasconcelos e Calado ${ }^{26}$, ocupa o quarto lugar na concentração de nutricionistas no País, consolidando e ampliando as áreas de atuação desses profissionais no campo das políticas públicas. Além disso, o campo da saúde coletiva é um ambiente propício para a interação com o campo da saúde mental que se desenvolveu fortemente na década de 1970 e início da década de 1980.

A despeito da área de atuação profissional, 
Neves et al. ${ }^{30(8)}$ alertam para o cuidado que precisa se ter na formação do nutricionista de forma que essa seja:

Marcada por oportunidades de aprendizagem em sociedade, nas quais o aluno possa desenvolver um espírito de pesquisa, de ideias críticas e inovadoras, tendo clara sua identidade profissional como membros de equipes multidisciplinares.

Dadas as características interdisciplinares do cuidado ao paciente com transtornos mentais, espera-se que o nutricionista atuante nos Caps priorize os aspectos subjetivos envolvidos na alimentação, olhando o indivíduo na sua totalidade, e não aquele dividido em órgãos e sistemas. No entanto, em grande parte, as demandas direcionadas a esse profissional obedecem ao modelo antigo de atenção, fragmentando o indivíduo de acordo com as especialidades.

Os nutricionistas têm sua identidade profissional centrada na dietética e, muitas vezes, apropriam-se das recomendações nutricionais sem conferir importância à complexa natureza da alimentação e cultura. Ao estabelecer uma prescrição dietética individualizada ${ }^{29}$, colocam-se como responsáveis pelo controle da alimentação do outro. As práticas cotidianas vinculadas à noção de território também constituem desafios nas concepções dos profissionais que muitas vezes reproduzem uma atenção para saúde voltada para o controle do outro ${ }^{30}$. Não é incomum, por exemplo, escutar um nutricionista dizer a um usuário do Caps "Como você engordou!", indicando que essa pode ser mais uma forma de se posicionar como profissional de nutrição da unidade do que uma real necessidade de emagrecimento do paciente.

Ao dirigirmos nossa atenção ao serviço de nutrição no Caps, observamos que as demandas ao profissional estão relacionadas com o modelo de atuação, na sua identidade e cultura profissionais. O nutricionista, ao procurar responder 'adequadamente' aos problemas relativos à alimentação e à saúde no cotidiano das pessoas, como comer 'melhor' para diminuir a obesidade ou controlar a hipertensão, entre tantos outros exemplos, possibilita a legitimação de suas práticas naquela sociedade.

Nos Caps, isso significa que, predominantemente, as solicitações de intervenção do nutricionista na alimentação são estritamente 'nutricionais' independentemente de 'onde' e 'como' se come. Constatamos solicitações de dietas para fins especiais, assim como o compromisso para 'vigiar' a quantidade de comida que será servida para os usuários. Também não é incomum o nutricionista conviver com inúmeros questionamentos pessoais sobre a melhor forma de se alimentar, qual a melhor dieta para ganhar peso, o melhor queijo para rechear os pães, como fazer uma dieta sem glúten para emagrecer, quais alimentos causam alergias alimentares ou qual suplemento alimentar é mais indicado para determinada situação, entre tantos outros. Ao nutricionista, são demandadas ações que envolvem especificamente questões clínicas, biologicistas, que tenham como foco os aspectos nutricionais do indivíduo, apagando toda subjetividade implicada no ato de se alimentar.

Nas reuniões de equipe multiprofissional, questões referentes à alimentação são debatidas ao final, e a demanda não é diferente do observado no modelo hegemônico. Os assuntos tratados sob uma perspectiva biomédica estão relacionados com a conduta nutricional para hipertensos, diabéticos, obesos, inclusive sobre a possibilidade de encaminhamento do paciente para cirurgia bariátrica. Espera-se uma intervenção prescritiva do nutricionista associado a uma terapêutica em saúde relativa a:

[...] um valor ideal, ou seja, daquela que busca restabelecer o estado habitual dos órgãos e seu estado ideal, depreende-se uma concepção dicotômica do evento saúde-doença [...]131(1348) 
O poder disciplinar produzido pela biomedicina atua na alimentação construindo uma estrutura valorativa em que se deve obedecer a regras nutricionais para manter um estado normal ${ }^{29}$. Dessa forma, sob esta perspectiva, discute-se a responsabilidade da instituição sobre os pacientes acolhidos, não devendo ser permitido 'burlar as regras'. Assim, devem ser repreendidas práticas como ir à padaria para comprar salgados ou esconder nos armários alimentos ultraprocessados, considerados danosos à saúde, como macarrão instantâneo, refrigerantes e biscoitos recheados.

Observa-se, no Caps, que há uma transposição do modelo hegemônico de atuação clínica do nutricionista para a instituição, independentemente dos objetivos desta e das características da população nela atendida, construindo uma prática descontextualizada. Para Kraemer et al.,

[...] do conjunto de representações, conhecimentos e práticas aprendidas e compartilhadas pelos indivíduos de um grupo social. Um ideal que ignora o sujeito, seu desejo, sua história de vida, seus prazeres cotidianos, afetos, compulsões e fobias, reduzindo-o a um ser que ingere calorias e nutrientes, esquecendo que a comida é símbolo de pertencimento familiar, cultural, social e existencial31(1349).

\section{Considerações finais}

Os profissionais da saúde mental, da nutrição, da gestão, da assistência social e da enfermagem, tidas aqui como funções e categorias profissionais distintas e autônomas, com formações específicas e visões de mundo nem sempre convergentes, encontram na mesa não apenas um lugar de diálogo, mas também um lugar de tensões e possibilidades terapêuticas, desde que estejam atentos e abertos para este olhar que respeita as diferenças e busca soluções negociadas para os problemas de cada território. Se cada um desses profissionais se fecha em seu campo de saber específico, não há diálogo possível; e quem perde é o usuário, pois, no Caps, a lógica das ciências médicas que coloca o corpo biológico como centro do tratamento não faz sentido: ela é capturada por outros sentidos - e só um olhar atento e informado pelas ciências sociais é capaz de produzir algum diálogo.

Cabe ainda interrogar o papel interventor da nutrição que se apoia no entendimento de que o Estado deverá garantir direitos mínimos aos cidadãos como renda mínima, saúde, habitação, educação, alimentação, entre outros. O profissional aí atua como fiscalizador, garantindo o cumprimento das medidas determinadas pelo Estado, por meio de leis, portarias, normas regulamentadoras, e assim por diante.

Esses desdobramentos do papel interventor do profissional nutricionista se evidenciam corriqueiramente nos espaços da saúde mental, em que a comida, por ser elemento de necessidade vital, muitas vezes é facilmente utilizada para manipular grupos de acordo com interesses de outros grupos que detêm o alimento. Muitas vezes, no campo da saúde mental, isso vai de encontro à valorização das escolhas individuais, visto que as instituições fornecem cardápios predefinidos, com horários preestabelecidos, reforçando um modelo engessado de cotidiano. Apesar de a alimentação ser considerada um evento biopsicossocial, é necessário também entrar no jogo, pois essa é mais uma forma de trazer à tona a comida para o debate, na tentativa de propor outros caminhos de cuidado.

Essas percepções do campo nos chamaram a atenção por haver um número significativo de novos profissionais, recém-formados em nutrição, que começam a ocupar esses espaços institucionais, sem uma formação que dê conta da complexidade da questão e sem dar os instrumentos necessários para que esse profissional recém-chegado no território perceba as nuances, os jogos de poder e os limites de cada formação. Nossa pesquisa, portanto, não 
apresenta uma resposta pronta, pelo contrário, ela amplia a percepção do problema e nos ajuda a refletir sobre o trabalho realizado pelo nutricionista nos Caps, subsidiando novas reflexões e novas práticas que favoreçam a consolidação das propostas da Reforma Psiquiátrica brasileira. Por fim, parece-nos importante ressaltar a necessidade de adequação dos serviços de alimentação coletiva como espaços de promoção da saúde, configurando um campo fértil para o desenvolvimento de uma perspectiva que integre múltiplos saberes, incluindo, aí, profissionais, usuários e familiares no manejo das problemáticas referidas ao campo da atenção psicossocial.

\section{Referências}

1. Brasil. Ministério da Saúde, Secretaria de Atenção à Saúde. Reforma psiquiátrica e política de saúde mental no Brasil. Documento apresentado à Conferência Regional de Reforma dos Serviços de Saúde Mental: 15 anos depois de Caracas. Brasília, DF: Opas; 2005.

2. Brasil. Ministério da Saúde. A Construção do SUS Histórias da Reforma Sanitária e do Processo Participativo. Brasília, DF: MS; 2006.

3. Amarante PDC. Reforma Psiquiátrica e Epistemologia. Cad. Bras. Saúde Mental. 2009; 1(1):1-7

4. Freire FHMA, Ugá MAD, Amarante P. Os Centros de Atenção Psicossocial e o impacto do sistema de financiamento no modelo assistencial. In: Amarante P. Archivos de saúde mental e atenção psicossocial 2. Rio de Janeiro: NAU; 2005.

\section{Colaboradores}

Almeida L (0000-0003-0210-8093)* contribuiu para o planejamento, revisão bibliográfica, concepção do texto e participou da aprovação da versão final do manuscrito. Seixas CM (0000-0003-2630-9746)* contribuiu para o planejamento, revisão bibliográfica, concepção de texto e participou da versão final do manuscrito. Ferreira FR (0000-00034504-3621)* contribuiu para o planejamento, concepção do texto e revisão crítica do conteúdo. Kraemer FB (0000-0002-3305-3358)* contribuiu para a concepção do texto, revisão crítica do conteúdo e participou da versão final do manuscrito.

5. Brasil. Lei $n^{0} 10.216$ de 6 de abril de 2001. Dispõe sobre a proteção e os direitos das pessoas portadoras de transtornos mentais e redireciona o modelo assistencial em saúde mental. Diário Oficial da União. 7 Abr 2001

6. Brasil. Constituição, 1988. Constituição da República Federativa do Brasil. Brasília, DF: Senado Federal; 1988.

7. Carvalho MCVS, Luz M, Prado SD. Comer, alimentar e nutrir: categorias analíticas instrumentais no campo da pesquisa científica. Ciênc. Saúde Colet. 2011; 16(1):155-163

8. Brasil. Ministério da Saúde. Política Nacional de Humanização [internet]. 2003. [acesso em 2018 mar 21]. Disponível em: http://www.saude.gov.br/humanizasus. 
9. Brasil. Ministério da Saúde. Portaria no 336 de 19 de fevereiro de 2002. Estabelece que os Centros de Atenção Psicossocial poderão constituir-se nas seguintes modalidades de serviços: CAPS I, CAPS II e CAPS III, definidos por ordem crescente de porte/complexidade e abrangência populacional. Diário Oficial da União. 20 Fev 2002.

10. Canesqui AM, Garcia RWD. Antropologia e nutrição: um diálogo possível. Rio de Janeiro: Fiocruz; 2005. (Coleção Antropologia e Saúde).

11. Boff L. Saber Cuidar: ética do humano - compaixão pela terra. Rio de Janeiro: Vozes; 1999.

12. Demétrio F, Paiva JB, Fróes AAG, et. al. A nutrição clínica ampliada e a humanização da relação nutricionista-paciente: contribuições para reflexão. Rev. Nutr. 2011; 24(5):743-763

13. Boutaud JJ. Comensalidade. Compartilhar a mesa. In: Montandon A. O livro da hospitalidade. São Paulo: Senac; 2011.

14. Brasil. Ministério da saúde, Secretaria de Atenção à Saúde. Ações Programáticas Estratégicas de Saúde Mental no SUS: os centros de atenção psicossocial. Brasília, DF: MS; 2004.

15. Silva EA, Costa II. O profissional de referência em Saúde Mental: das responsabilizações ao sofrimento psíquico. Rev. latinoam. psicopatol. fundam. 2010; 13(4):635-647.

16. Ishige N. El hombre comensal. Correio Unesco. 1987; 15(7):18-21.

17. Elias N. O processo civilizador. Uma história dos costumes. Rio de Janeiro: Jorge Zahar; 1994. (V. 1).

18. Goffmann E. Estigma - Notas sobre a manipulação da identidade deteriorada, 1891. Tradução: Mathias Lambert, 2004; 2007.

19. Castro HC, Maciel ME. Entre laços, afetos e subjetividades: a comensalidade em uma Cozinha Comunitária. In: Anais da 30ª Reunião Brasileira de An- tropologia; 2016 ago 3-6; João Pessoa. João Pessoa: Associação brasileira de Antropologia; 2016.

20. Geertz C. A Interpretação das Culturas. Rio de Janeiro: Guanabara Koogan; 1989.

21. Conselho Regional de Nutricionistas $4^{\mathrm{a}}$ Região. Conselho: o início [internet]. [acesso em 2018 ago 18]. Disponível em: www.crn4.gov.br.

22. Toloza DC. Nutricionista: um histórico da profissão até os dias atuais. [monografia]. Brasília, DF: Universidade de Brasília. Centro de Excelência em Turismo; $2003.68 \mathrm{f}$.

23. L'abbate S. As Políticas de Alimentação e Nutrição no Brasil: I. Período de 1940 a 1964. Rev. Nutr.1988; $1(2): 87-138$

24. Conselho Federal de Nutricionistas. A História do Nutricionista no Brasil [internet]. [acesso em 2014 maio 16]. Disponível em: https://www.cfn.org.br/ wp-content/uploads/repositorioa/Comunicacao/ Material_institucional/160.pdf.

25. Associação Brasileira de Nutrição. Início [internet]. 2014. [acesso em 2015 maio 28] Disponível em: http:// www.asbran.org.br/index.php.

26. Vasconcelos FAG, Calado CLA. Profissão nutricionista: 70 anos de história no Brasil. Rev. Nutr. 2011; 24(4):605-617.

27. Vasconcelos FAG. O nutricionista no Brasil: uma análise histórica. Rev. Nutr. 2002; 15(2):127-138.

28. Conselho Federal de Nutricionistas. CFN. Resolução $\mathrm{n}^{\mathrm{o}} 600$ de 25 de fevereiro de 2018 [internet]. Dispõe sobre a definição das áreas de atuação do nutricionista e suas atribuições, indica parâmetros numéricos mínimos de referência, por área de atuação, para a efetividade dos serviços prestados à sociedade e dá outras providências. Diário Oficial da União. $20 \mathrm{Abr}$ 2018. [acesso em 24 fev 2020]. Disponível em: https://www.cfn.org.br/wp-content/uploads/resolucoes/Res_600_2018.htm. 
29. Campos FM, Prado SD, Kraemer FB, et al. Scenario of research on Food Service in Brazil. Rev. Nutr [internet]. 2017 [acesso em 2020 ago 20]; 30(1):1-12. Disponível em: https://www.scielo.br/scielo.php?script=sci arttext\&pid=S1415-52732017000100001.

30. Neves J, Zanlourensi CB, Domene SMA, et al. Eighty years of undergraduate education in nurition in Brazil: An analysis of the 2009-2018 period. Rev. Nutr [internet]. 2019 [acesso em 2020 ago 20]; (32):e180158. Disponível em: https:// www.scielo.br/scielo.php?script=sci_arttext\&pid $=$ S1415-52732019000100303.

31. Kraemer FB, Prado SD, Ferreira FR, et al. O discurso sobre a alimentação saudável como estratégia de biopoder. Physis. 2014; 24(4):1337-1359.

Recebido em 29/02/2020

Aprovado em 28/08/2020

Conflito de interesses: inexistente

Suporte financeiro: Fundação de Amparo à Pesquisa do Estado do Rio de Janeiro (Faperj). Processo no 202.734/2017 